\title{
Role of the Endogenous Kallikrein-Kinin System in
}

\section{Modulating Vasopressin-stimulated Water Flow and}

\section{Urea Permeability in the Toad Urinary Bladder}

\author{
Christos P. Carvounis, Georgia Carvounis, and Leonard A. Arbeit, Department \\ of Medicine, Division of Nephrology and Hypertension, State University of \\ New York at Stony Brook, Stony Brook, New York 11794
}

\begin{abstract}
A B S T R A C T This study investigates the endogenous kallikrein-kinin system's role as a modulator of vasopressin action in the toad urinary bladder. Kallikrein inhibition by aprotinin, which results in decreased kinin production, significantly increased both vasopressin and 8-Br-cyclic (c) AMP-stimulated water flow. Kinin potentiation by the kininase II inhibitor captopril (SQ 14225) significantly decreased vasopressin and 8-Br-cAMP-stimulated water flow. In contrast to water flow, vasopressin-stimulated urea permeability was decreased by aprotinin and increased by captopril. We conclude that the endogenous kallikrein-kinin system represents a significant modulator of vasopressin action and it permits separate control of vasopressin-stimulated water flow and solute transport.
\end{abstract}

\section{INTRODUCTION}

The action of vasopressin on transepithelial water transport has been shown to be modulated by several hormonal systems including aldosterone (1) and prostaglandins $(2,3)$. Several lines of indirect evidence

Presented in part at the 12th Annual Meeting of the American Society of Nephrology, Boston, 1979, and 72nd Annual Meeting of The American Society of Clinical Investigation, Washington, D. C., 10 May 1980.

Received for publication 26 January 1981 and in revised form 20 March 1981. suggest that the kallikrein-kinin system may also modulate the action of vasopressin. The infusion of kinin in vivo has been shown to increase free water clearance (4). An increase in kallikrein excretion accompanies an increase in free water clearance $(5,6)$. Moreover, kallikrein has been shown to be located on the luminal membrane of the distal convoluted tubule and collecting duct of the mammalian nephron $(7,8)$, the major site of vasopressin's action. An endogenous kallikrein-kinin system has also been identified in the toad urinary bladder $(9,10)$, a close analogue of the mammalian distal nephron. Furthermore, Furtado (11) has reported that exogenous bradykinin decreases vasopressin-stimulated water flow in the amphibian urinary bladder.

Stimulated by these previous observations, we examined the hypothesis that the endogenous kallikrein-kinin system is a physiological modulator of vasopressin-stimulated water and solute transport. The results demonstrate that inhibition of the endogenous kallikrein-kinin system augments vasopressin-stimulated water flow but depresses vasopressin-stimulated urea transport, whereas activation of the endogenous kallikrein-kinin system depresses vasopressin-stimulated water transport but augments vasopressin-stimulated urea permeability. The opposite effects of the kallikrein-kinin system on vasopressinstimulated water and urea transport makes this endogenous modulator system distinct from aldosterone and prostaglandins, both of which alter water and urea transport in the same direction $(1,3)$. 


\section{METHODS}

Female Dominican toads (National Reagents, Bridgeport, Conn.) were doubly pithed, and glass bongs were tied into both hemibladders in situ. The bladders were excised and washed three times with amphibian phosphate Ringer's solution ( $120 \mathrm{mM} \mathrm{Na}^{+}, 4$ meq K $\mathrm{K}^{+}, 0.5 \mathrm{mM} \mathrm{Ca}^{++}, 116$ meq Cl, 5 $\mathrm{mM}$ phosphate, osmolality $240 \mathrm{mosmol} / \mathrm{kg}, \mathrm{pH} 7.4)$. They were finally filled with $8 \mathrm{ml}$ buffered distilled water $(0.5 \mathrm{mM}$ sodium phosphate, $\mathrm{pH} \mathrm{7.4)}$ and suspended in a bath containing $35 \mathrm{ml}$ Ringer's solution.

Aprotinin, an inhibitor of kallikrein $(8,12)$ was added at a concentration of 600 kallikrein inhibition units $(\mathrm{KIU}) / \mathrm{ml}(91$ $\mu \mathrm{M})$ to the mucosal solution of experimental hemibladders. The control hemibladder was treated with vehicle. After $1 \mathrm{~h}$ of incubation the mucosal and serosal solutions of both experimental and control hemibladders were replaced with fresh solutions of identical composition to remove any preformed kinins. The bladders were allowed to equilibrate for 15-30 min and then osmotic water flow and urea permeability were determined at 15-min intervals. After obtaining base-line observation for two 15 -min periods, the response to vasopressin stimulation was determined. In separate experiments we examined the response of 8-Bromocyclic(c)AMP (8-Br-cAMP) on osmotic water flow and urea transport. The concentration of vasopressin or 8-Br-cAMP used in different experiments is shown in Results for each type of experiment.

In another group of hemibladders prepared as above, the activity of the endogenous kallikrein-kinin system was potentiated by the kininase II inhibitor (13), captopril (SQ 14225, Squibb Laboratories, Div. E. R. Squibb \& Sons, Princeton, N. J.). The inhibitor was added to the mucosal solution of the experimental hemibladders at a concentration of $100 \mu \mathrm{g} / \mathrm{ml}$. Both hemibladders were preincubated $1 \mathrm{~h}$ before measurement of vasopressin-stimulated water flow and urea permeability. Captopril inhibits kininase II activity (13). In cells scraped from the bladder and osmotically ruptured, this dose of captopril inhibits $90-100 \%$ of the degradation of bradykinin (unpublished findings).

Osmotic water flow was measured gravimetrically (14). The urea permeability coefficient $\left(\mathrm{K}_{\text {trans urea }}\right)$ was determined by sampling the serosal and mucosal solutions at 15-min intervals (15). Samples were pipetted into liquicint (National Diagnostics, Somerville, N. J.) and counted in a Beckman LS8000 scintillation counter (Beckman Instruments, Inc., Fullerton, Calif.)

Aprotinin was kindly provided in crystal form by Dr. Gert Haberland, Beyer Pharmaceutical, Munich, West Germany. Captopril was a gift of Dr. Z. F. Horovitz, Squibb Laboratories. Fresh solutions of these compounds were prepared daily. Vasopressin and 8-Br-cAMP were purchased from Sigma Chemical Co., St. Louis, Mo. ${ }^{14} \mathrm{C}$-urea was purchased from New England Nuclear, Boston, Mass.

Comparisons between control and experimental hemibladders were done by paired $t$ test.

\section{RESULTS}

In hemibladders containing aprotinin in the mucosal solution water transport was augmented in response to a low dose $(2 \mathrm{mU} / \mathrm{ml})$ or supramaximal dose $(50 \mathrm{mU} / \mathrm{ml})$ of vasopressin compared with the paired controls (Table I). Aprotinin-treated bladders also exhibited increased water transport in response to 8-Br-cAMP (Table I). Addition of aprotinin to the serosal solution
TABLE I

Effect of Aprotinin (91 $\mu \mathrm{M}$ ) on Base-line and Stimulated Water Transport

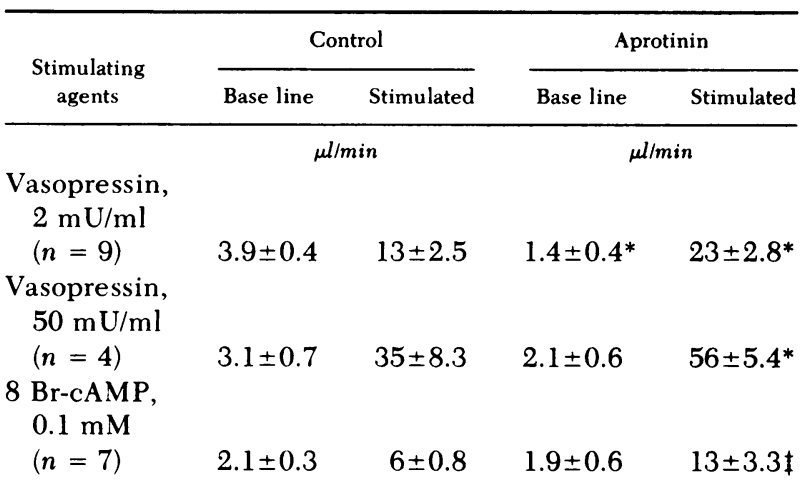

Comparisons are between control and experimental hemibladders.

${ }^{*} P<0.01 ; \ddagger P<0.005$. Data are expressed as mean $\pm \mathrm{SEM}$.

had no effect on water transport (not shown). The dose of aprotinin used in these experiments, $91 \mu \mathrm{M}(600$ $\mathrm{KIU} / \mathrm{ml}$ ), produced a maximal increase in vasopressinmediated water flow $99 \pm 19 \%$ of control $(n=15)$. A dose of $40 \mu \mathrm{M}(250 \mathrm{KIU} / \mathrm{ml})$ caused a $51 \pm 15 \%$ increase in water flow $(n=4)$, whereas there was no consistent increase in water flow when $15 \mu \mathrm{M}(100 \mathrm{KIU} / \mathrm{ml})$ or less aprotinin was used $(n=9)$.

In hemibladders containing captopril or in the mucosal solution, water transport in response to a low dose $(2 \mathrm{mU} / \mathrm{ml})$ or supramaximal dose $(50 \mathrm{mU} / \mathrm{ml})$ of vasopressin was reduced $\sim 33 \%$ below that of the paired-control hemibladders (Table II). A similar decrease was observed in response to stimulation by 8-Br-cAMP (Table II). In these experiments $1 \mathrm{mM}$ was

TABLE II

Effect of Captopril (100 $\mu \mathrm{g} / \mathrm{ml})$ on Base-line and Stimulated Water Transport

\begin{tabular}{|c|c|c|c|c|}
\hline \multirow{2}{*}{$\begin{array}{c}\text { Stimulating } \\
\text { agents }\end{array}$} & \multicolumn{2}{|c|}{ Control } & \multicolumn{2}{|c|}{ Captopril } \\
\hline & Base line & Stimulated & Base line & Stimulated \\
\hline & \multicolumn{2}{|c|}{$\mu l / \min$} & \multicolumn{2}{|c|}{$\mu l / \min$} \\
\hline$(n=10)$ & $1.6 \pm 0.1$ & $14.9 \pm 1.1$ & $1.3 \pm 0.1$ & $9.4 \pm 1.5^{*}$ \\
\hline $\begin{array}{c}\text { Vasopressin, } \\
50 \mathrm{mU} / \mathrm{ml} \\
(n=6)\end{array}$ & $1.8 \pm 0.4$ & $32.7 \pm 4.1$ & $1.7 \pm 0.2$ & $25.5 \pm 5.6 \ddagger$ \\
\hline $\begin{array}{c}8 \text { Br-cAMP, } \\
1 \mathrm{mM} \\
(n=9)\end{array}$ & $1.5 \pm 0.2$ & $50.1 \pm 5.2$ & $1.0 \pm 0.3$ & $37.5 \pm 6.3 \ddagger$ \\
\hline
\end{tabular}

Comparisons are between control and experimental hemibladders.

${ }^{*} P<0.01 ; \ddagger P<0.05$. Data are expressed as mean \pm SEM. 
used rather than $0.1 \mathrm{mM}$ as in the aprotinin experiments to magnify the absolute difference in water flow between the control and captopril-treated hemibladders. In a few experiments performed with $0.1 \mathrm{mM}$ 8-Br-cAMP, captopril diminished osmotic water flow to a similar extent; however, the absolute change was small.

In a separate set of experiments the effect of aprotinin on vasopressin-stimulated urea permeability was examined. Aprotinin had no effect on base-line urea permeability, whereas in response to vasopressin $(2 \mathrm{mU} / \mathrm{ml})$ urea permeability was significantly reduced compared with that of the control hemibladders (Fig. 1). As shown in Fig. 1 the diminished vasopressinstimulated water flow was seen in these hemibladders.

In captopril-treated hemibladders urea permeability was increased in response to vasopressin $(50 \mathrm{mU} / \mathrm{ml})$, whereas vasopressin-stimulated water transport was reduced (Fig. 2).

\section{DISCUSSION}

In these experiments we sought to determine whether the endogenous kallikrein-kinin system might function as a modulator of vasopressin's action on water and solute transport. Studies were performed in the toad urinary bladder because the action of vasopressin on water and urea transport has been well characterized in this tissue and it has been shown that the toad urinary bladder contains an endogenous kallikrein-kinin system. We used an experimental design in which the effects of inhibiting as well as potentiating the activity of the endogenous kallikrein-kinin system on vasopressin-stimulated water and urea transport could be examined. To depress the activity of the kallikreinkinin system we added aprotinin (a competitive inhibitor of kallikrein) to the solution bathing the mucosal bladder. This agent would be expected to decrease kinin production. Potentiation of the endogenous kallikrein-kinin system was accomplished by the addition to the mucosal solution of captopril, an inhibitor of kininase II, a kinin degrader.

We found that addition of aprotinin, which should diminish kinin production, was associated with significant increases in vasopressin and cAMP-stimulated water flow. Conversely, addition of captopril, which should augment kinin levels, was associated with significant decreases in vasopressin and cAMPstimulated water flow. Although kinins were not measured in these experiments, these results are consistent with the view that the alterations in vasopressin and CAMP-stimulated water flow were causally related to reciprocal changes in kinin production. Indeed a naturally occurring amphibian kinin, physalaemin, in a concentration of $30 \mu \mathrm{M}$ completely reverses aprotinin's stimulation of water flow (unpublished observation).

Our findings extend the observations of previous studies in intact animals in that they demonstrate a direct effect of the kallikrein-kinin system on water transport independent of changes in renal hemodynamics or distal tubular delivery of filtrate. Our studies also extend Furtado's (11) observations with exogenous kinin in that they demonstrate that altera-

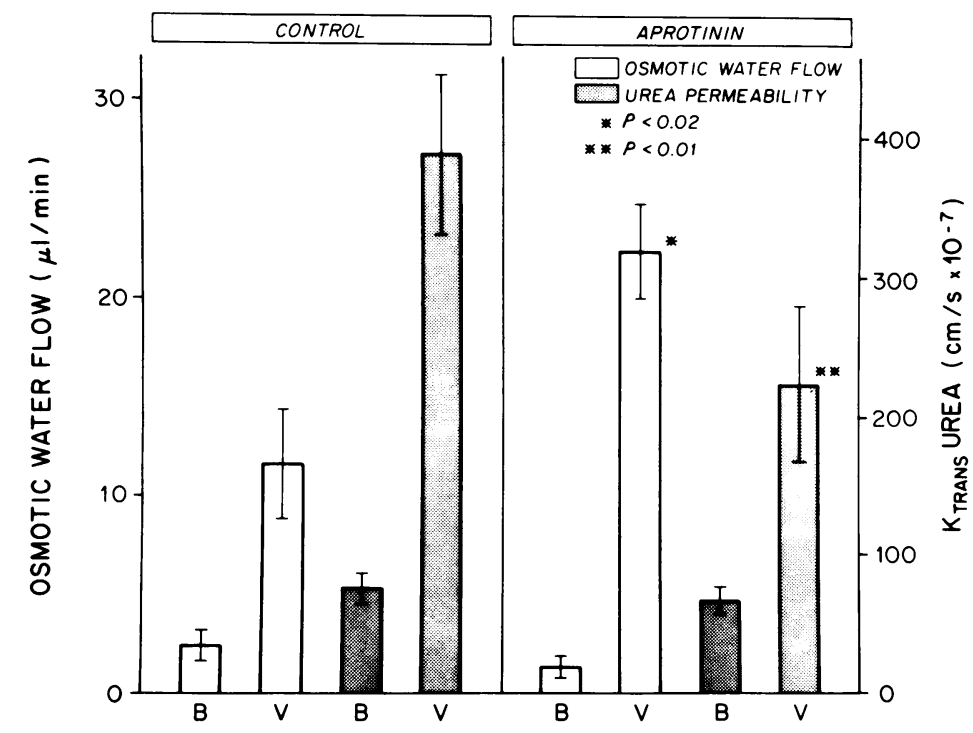

FIGURE 1 Effects of $91 \mu \mathrm{M}$ aprotinin on $2 \mathrm{mU} / \mathrm{ml}$ vasopressin-stimulated water flow and urea permeability $(n=6)$. B represents base-line periods whereas $\mathrm{V}$ represents vasopressin-stimulated periods. Statistical analyses compare control vs. aprotinin-treated bladders. 


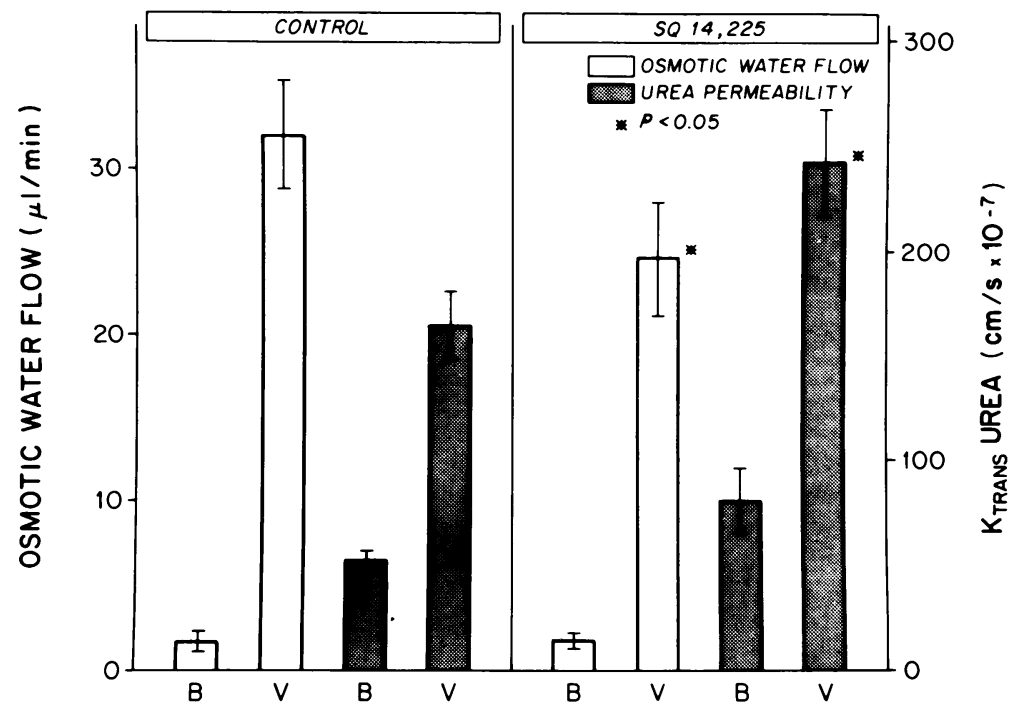

FIGURE 2 Effect of $100 \mu \mathrm{g} / \mathrm{ml}$ (captopril) on $50 \mathrm{mU} / \mathrm{ml}$ vasopressin-stimulated water flow and urea permeability $(n=7)$. B represents base-line periods, whereas $\mathrm{V}$ represents vasopressinstimulated periods. Statistical analyses compare control vs. SQ 14225 periods.

tions in activity of the endogenous kallikrein-kinin system can modulate the action of vasopressin.

It should be noted that our findings are at variance with a recent report by Orce et al. (12) who examined the effect of kallikrein inhibitors on sodium transport and found that aprotinin had no effect on vasopressinstimulated water flow. Several reasons may account for the differences between studies, including the fact that a different species of toad was used by Orce et al. (12) (Mexican and Puerto Rican toads compared with Dominican toads as used in our study) as well as the magnitude of water flow. In their study water flow was approximately one order of magnitude greater than that obtained in our studies when normalized for differences in surface area. Thus, it may be that aprotinin had no detectable effect on water flow because water flow was already at maximal levels or that endogenous kinin levels in their toads were significantly lower than those present in our experiments.

We also obtained evidence that the endogenous kallikrein-kinin system can modulate vasopressin's action on urea permeability; however, the effects of alterations of endogenous kinin production on vasopressin-stimulated urea permeability were opposite in direction to the effects of endogenous kinins on vasopressin-stimulated water transport. Thus, inhibition of kinin production by aprotinin reduced vasopressin's effect to increase urea permeability, whereas augmenting kinin production with captopril potentiated the increase in urea permeability stimulated by vasopressin. Previous studies have provided evidence for the concept that the pathways mediating water and urea transport are to a significant extent independent and distinct from one another $(3,16,17)$. This concept is strengthened by the original observation of this study that endogenous kinins modulate vasopressin's action on the water and urea transport pathways in opposite directions. The ability of kinins to modify vasopressin's action on water flow and urea permeability in opposite directions could promote increased urea transport at a time when water transport was attenuated. Thus, the endogenous kallikrein-kinin system may provide a mechanism for conserving important solutes, such as urea, while permitting excretion of water.

Our observation that the endogenous kallikreinkinin system can modulate water and urea transport coupled with the recent finding that vasopressin augments kallikrein activity in vivo (18) provides support for the hypothesis that the endogenous kallikrein-kinin system may function as a negative feedback mechanism for regulating vasopressin-stimulated water transport. Thus, in addition to stimulating adenylate cyclase activity and cAMP production, vasopressin may also increase kallikrein activity and thereby promote increased kinin production. Kinins in turn appear to act at a step distal to the generation of cAMP to attenuate water transport, whereas urea transport is enhanced.

\section{ACKNOWLEDGMENT}

The authors are indebted to Dr. George Kaloyanides for his help in the preparation of this manuscript. We would also like to thank Ms. Beverly Calligheris for secretarial assistance.

This work was supported in part by grants from New York State Health Research Council K-020, National Institutes of 
Health 1 ROl AM 27481-01, and the New York Kidney Foundation.

\section{REFERENCES}

1. Handler, J. S., A. S. Preston, and J. Orloff. 1969. Effect of adrenal steroid hormones on the response of the toad's urinary bladder to vasopressin. J. Clin. Invest. 48: 823833.

2. Zussman, R. M., H. R. Keiser, and J. S. Handler. 1977. Vasopressin-stimulated prostaglandin $\mathrm{E}$ biosynthesis in the toad urinary bladder. Effect on water flow. J. Clin. Invest. 60: 1339-1347.

3. Carvounis, C. P., N. Franki, S. D. Levine, and R. M. Hays. 1979. Membrane pathways for water and solutes in the toad bladder. I. Independent activation of water and urea transport. J. Membr. Biol. 49: 253-268.

4. Webster, M. E., and J. P. Gilmore. 1964. Influence of kallidin on renal function. Am. J. Physiol. 206: 714-718.

5. Adetuybi, A., and I. H. Mills. 1972. Relations between urinary kallikrein and renal function, hypertension and excretion of sodium and water in man. Lancet. I: 203207.

6. Arbeit, L. A., D. B. Bernard, P. Johnston, and N. G. Levinsky. 1978. Human kallikrein excretion during alterations of salt and water balance: reassessment by a new specific immunoassay. Clin. Res. 27: 494a. (Abstr.)

7. Ostravik, T. B., K. Nustad, P. Brandtzaeg, and J. V. Pierce. 1976. Cellular origin of urinary kallikrein. J. Histochem. Cytochem. 24: 1037-1039.

8. Chao, J., and H. S. Margolius. 1979. Studies on rat renal cortical cell kallikrein. II. Identification of kallikrein as an ecto-enzyme. Biochim. Biophys. Acta. 570: 330-340.

9. Furtado, M. R. F. 1972. Occurrence of a kinin-like peptide in the urinary bladder of the toad. Bufo marinus paracnemis Lutz. Biochem. Pharmacol. 21: 118-129.

10. Margolius, H. S., and J. Chao. 1980. Amiloride inhibits mammalian renal kallikrein and kallikrein-like enzyme from toad bladder and skin.J. Clin. Invest. 65: 1343-1350.

11. Furtado, M. R. F. 1971. Inhibition of the permeability response to vasopressin and oxytocin in the toad bladder: effect of bradykinin, kallidin, eleodosin and physalamine. J. Membr. Biol. 4: 167-178.

12. Orce, G., G. Castillo, and H. S. Margolius. 1980. Inhibition of shortcircuit current in toad urinary bladder by inhibitors of glandular kallikrein. Am.J. Physiol. 239: F459F465.

13. Ondetti, M., B. Rubin, and D. W. Cushman. 1977. Design of specific inhibitors of angiotension converting enzyme. New class of orally active antihypertensive agents. Science (Wash. D. C.). 196: 441-444.

14. Bentley, P. M. 1958. The effects of neurohypophyseal extracts on water transfer across the wall of the isolated urinary bladder of the toad Bufo marinus. J. Endocrinol. 17: 201-209.

15. Maffly, R. H., R. M. Hays, E. Landin, and A. Leaf. 1960. The effect of neurohypophyseal hormone on the permeability of the toad bladder to urea. J. Clin. Invest. 39: 630-641.

16. Carvounis, C. P., S. D. Levine, and R. M. Hays. 1979. pH dependence of water and solute transport in toad urinary bladder. Kidney Int. 15: 513-519.

17. Carvounis, C. P., S. D. Levine, N. Franki, and R. M. Hays. 1980. Membrane pathways for water and solutes in the toad bladder. II. Reflection coefficients of the water and solute channels. J. Membr. Biol. 49: 269-281.

18. Fejes-Toth, G., T. Zahajszky, and J. Filep. 1980. Effect of vasopressin on renal kallikrein excretion. Am. J. Physiol. 239: F388-F392 